\title{
The prevalence and characteristics of microalbuminuria in the general population: a cross-sectional study
}

\author{
Satoru Tanaka', Hiroyuki Takase ${ }^{2}$, Yasuaki Dohi ${ }^{*}$ and Genjiro Kimura ${ }^{1,3}$
}

\begin{abstract}
Background: Microalbuminuria is a marker of cardiovascular events. This study investigated the prevalence of microalbuminuria in the general population and the factors that can affect urinary excretion of albumin.

Methods: Apparently healthy subjects who participated in a health checkup at our hospital were enrolled in this study ( $\mathrm{n}=7963$, male 64.0\%, $56.2 \pm 11.8$ years old) Urine samples were collected for the measurement of albumin concentrations, which were expressed as the ratio of urinary albumin to creatinine concentrations (UACR [mg/g Cr]). Individual salt intake was assessed by estimating the 24-hour urinary salt excretion of subjects.

Results: The mean blood pressure was $124 \pm 15 / 76 \pm 10 \mathrm{mmHg}$ and $31.6 \%, 7.4 \%$, and $44.1 \%$ of subjects had hypertension, diabetes mellitus, and dyslipidemia, respectively. Urinary albumin was detected in 7265 subjects (91.2\%: UACR $\geq 300 \mathrm{mg} / \mathrm{g} \mathrm{Cr}, 0.5 \% ; 300>\mathrm{UACR} \geq 30 \mathrm{mg} / \mathrm{g} \mathrm{Cr}, 4.6 \% ; 30>$ UACR $\geq 20 \mathrm{mg} / \mathrm{g} \mathrm{Cr}, 2.4 \% ; 20>$ UACR $\geq 10 \mathrm{mg} / \mathrm{g} \mathrm{Cr}, 8.7 \% ; 10>$ UACR $\geq 5 \mathrm{mg} / \mathrm{g} \mathrm{Cr}, 21.8 \% ; \mathrm{UACR}<5 \mathrm{mg} / \mathrm{g} \mathrm{Cr}, 53.2 \%)$. In subjects with detectable albuminuria, UACR was independently correlated with age, systolic blood pressure, serum creatinine, fasting plasma glucose, and salt intake after adjustment for possible factors $(P<0.0001)$.

Conclusion: The prevalence of microalbuminuria was found to be $4.6 \%$ in the general population. The urinary excretion of albumin was closely associated with blood pressure and salt intake. These data indicated the importance of salt restriction for the prevention of cardiovascular disease and end-stage renal disease.
\end{abstract}

Keywords: Blood pressure, General population, Hypertension, Microalbuminuria, Salt

\section{Background}

Recent studies have established that microalbuminuria is an important cardiovascular risk factor [1,2]. Clinical data have demonstrated that left ventricular hypertrophy, increased intima-media thickness of the carotid artery, and subclinical cardiovascular diseases are associated with microalbuminuria among individuals at high risk for cardiovascular disease [3-5]. Furthermore, epidemiological and experimental studies have established that high levels of urinary albumin excretion are associated with an increased incidence of cardiovascular mortality as well as mortality from all causes [6]. Most of these data came from observations involving high-risk

\footnotetext{
*Correspondence: ydohi@med.nagoya-cu.ac.jp

1 Department of Cardio-Renal Medicine and Hypertension, Nagoya City

University Graduate School of Medical Sciences, Nagoya, Japan

Full list of author information is available at the end of the article
}

patients. The association between urinary albumin levels and increased cardiovascular mortality in high-risk patients is evident even at urinary albumin levels below the clinically defined threshold for microalbuminuria.

Urinary albumin excretion is also a predictor of mortality from all causes in the general population [7]. The excess risk is more attributable to death from cardiovascular causes and this relationship is already apparent at 'normal' levels of albuminuria $[3,8]$. The establishment of an association between urinary excretion of albumin and cardiovascular morbidity and mortality in the general population may support the measurement of urinary albumin as a cardiovascular disease marker. This would enable the identification of individuals who may benefit from aggressive risk reduction for the primary prevention of cardiovascular disease. Thus, the present study investigated the range of urinary excretion levels for

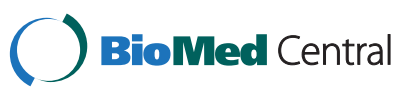


albumin and the prevalence of microalbuminuria. Through these data we sought to identify factors that may affect urinary excretion of albumin in the general population.

\section{Methods}

The study was performed in accordance with the principles of the Declaration of Helsinki, and the Ethics Committee of Enshu Hospital approved the study protocol. Written informed consent was obtained from all subjects prior to the start of the study.

\section{Study settings and subjects}

A total of 8155 persons who visited our hospital for a yearly physical checkup from April 2010 to March 2011 were screened for eligibility to be included in the present study. Subjects with incomplete data were excluded and the rest of the 7963 subjects were finally included in the present study. In addition to the routine examination of subjects in our health checkup program (physical examination, chest X-ray, electrocardiogram [ECG], and laboratory assessment of cardiovascular risk factors), urine was sampled for the measurement of urinary albumin in the morning after an overnight fast. Cross-sectional analyses were performed in order to investigate the prevalence of albuminuria and factors closely related to the urinary excretion of albumin.

Urinary albumin concentrations were measured by a turbidimetric immunoassay (analytical range $\geq 1.1 \mathrm{mg} / \mathrm{L}$ ) and are expressed as the ratio of concentrations of urinary albumin to urinary creatinine (UACR $[\mathrm{mg} / \mathrm{g} \mathrm{Cr}]$ ). UACR was recorded as $0 \mathrm{mg} / \mathrm{g} \mathrm{Cr}$ in those subjects with a urinary albumin concentration below the analytical limit. Microalbuminuria was defined according to the recommendation of the American Diabetes Association and the National Kidney Foundation $(300>$ UACR $\geq 30 \mathrm{mg} / \mathrm{g} \mathrm{Cr})$ $[9,10]$. Individual salt intake was assessed by estimating the 24-hour urinary salt excretion of subjects and it was calculated using a previously reported formula [11].

Blood pressure was measured by a standard sphygmomanometer, after subjects were seated in a chair for $5 \mathrm{~min}$ with their backs supported as well as their arms supported at heart level. Proper cuff size was determined based on arm circumference. Three consecutive blood pressure measurements were taken, with two minutes between each measurement, and the mean of the second and third measurements was recorded as the blood pressure. Hypertension was defined as systolic blood pressure (SBP) $\geq 140$ $\mathrm{mmHg}$ and/or diastolic blood pressure (DBP) $\geq 90$ $\mathrm{mmHg}$, or the use of antihypertensive medications. In this study, diabetes mellitus was defined as fasting plasma glucose $\geq 126 \mathrm{mg} / \mathrm{dL}$ or the use of anti-diabetic medications and dyslipidemia was defined as low-density lipoproteincholesterol (LDL-cholesterol) $\geq 140 \mathrm{mg} / \mathrm{dL}$, high-density lipoprotein-cholesterol (HDL-cholesterol) $<40 \mathrm{mg} / \mathrm{dL}$, triglyceride $\geq 150 \mathrm{mg} / \mathrm{dL}$, or the use of antidyslipidemic medications [12]. ECGs were recorded after subjects had rested for $1 \mathrm{~min}$ in the supine position in an airconditioned room.

\section{Statistical analysis}

All statistical analyses were performed using StatView 5.0 (SAS Institute, Inc., Cary, USA). Data in the text and the tables were expressed as mean \pm standard deviation. Because the distribution of UACR was skewed rightward, these values were expressed as median \pm absolute deviation and were log-transformed before statistical analysis. Differences between two groups were compared by unpaired Student's $t$ tests. A corrected chi-square test was used for comparisons between categorical data. Subjects were divided into six groups (Figure 1) according to their urinary level of albumin. The relationship between urinary excretion of albumin and blood pressure, fasting plasma glucose, or salt intake was investigated (ANOVA followed by Scheffe's post-hoc analysis). Univariate and multivariate regression analyses were performed in order to investigate the relationship between urinary levels of albumin and other variables. A $P$ value of less than 0.05 was considered to be statistically significant.

\section{Results}

The characteristics of all study subjects are shown in Table 1, with 31.6\% having hypertension, $7.4 \%$ having diabetes mellitus, and $44.1 \%$ having dyslipidemia. Of the subjects with these conditions, $66.3 \%, 67.9 \%$, and $26.0 \%$, respectively, were under medical treatment for the disorder. A total of 1642 subjects (20.6\%) were overweight (body mass index (BMI) $>25 \mathrm{~kg} / \mathrm{m}^{2}$. Urinary albumin was detected in most subjects $(\mathrm{n}=7265,91.2 \%)$. More than half of the subjects (53.2\%), had minimal excretion levels of albumin (UACR $<5 \mathrm{mg} / \mathrm{g} \mathrm{Cr}$ ) and about $4.6 \%$ of subjects showed microalbuminuria $(300>\mathrm{UACR} \geq 30 \mathrm{mg} / \mathrm{g}$ Cr) (Figure 1).

Regression analyses were performed in a subgroup of subjects with detectable urinary albumin (urinary albu$\min \geq 1.1 \mathrm{mg} / \mathrm{L} ; \mathrm{n}=7265,91.2 \%)$. Using univariate regression analysis, UACR was correlated with age, male gender, waist circumference, BMI, SBP, serum creatinine, uric acid, fasting plasma glucose, dyslipidemia, salt intake, ECG voltage, and use of inhibitors of the reninangiotensin system (Table 2). Age, male gender, SBP, serum creatinine, fasting plasma glucose, salt intake, smoking status, ECG voltage, and use of inhibitors of the renin-angiotensin system were independent predictors of urinary albumin among the variables that show close correlation with urinary excretion of albumin after adjustment for possible factors listed in Table 3. Similar results were obtained in an analysis where all subjects $(n=7963)$ were included in the regression model that 


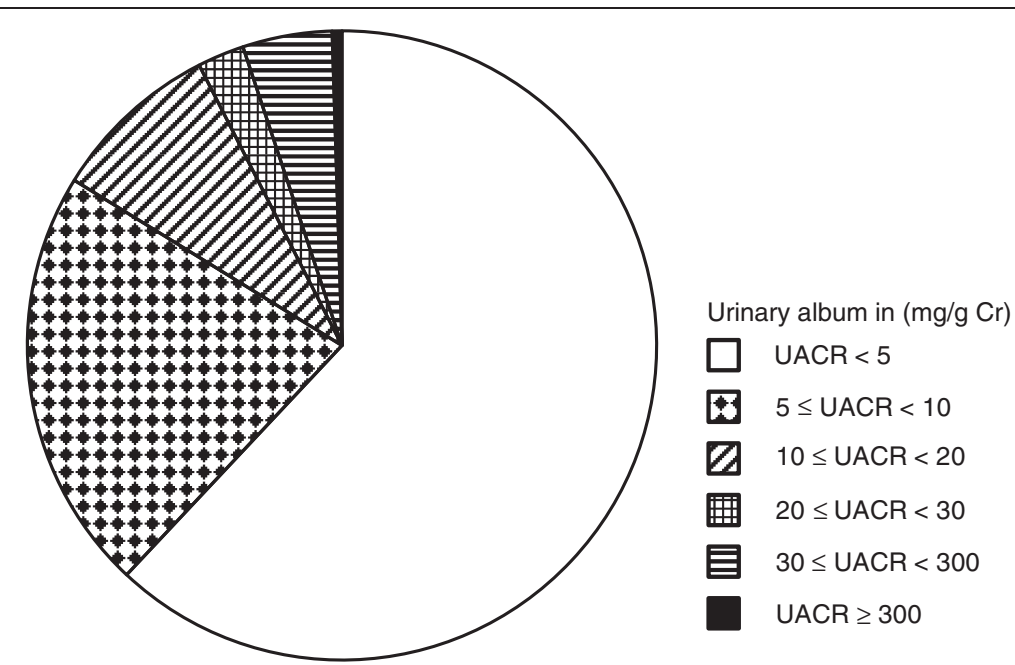

Figure 1 Distribution of urinary levels of albumin. Urinary albumin was detected in 7265 subjects (UACR $\geq 300 \mathrm{mg} / \mathrm{g} \mathrm{Cr}, \mathrm{n}=41,0.5 \% ; 300>$ UACR $\geq 30 \mathrm{mg} / \mathrm{g} \mathrm{Cr}, \mathrm{n}=362,4.6 \% ; 30>$ UACR $\geq 20 \mathrm{mg} / \mathrm{g} \mathrm{Cr}, \mathrm{n}=192,2.4 \% ; 20>$ UACR $\geq 10 \mathrm{mg} / \mathrm{g} \mathrm{Cr}, \mathrm{n}=694,8.7 \% ; 10>$ UACR $\geq 5 \mathrm{mg} / \mathrm{g} \mathrm{Cr}$, $\mathrm{n}=1737,21.8 \% ; \mathrm{UACR}<5 \mathrm{mg} / \mathrm{g} \mathrm{Cr}, \mathrm{n}=4239,53.2 \%$ ). $\cup A C R$ indicates the ratio of the concentrations of urinary albumin to urinary creatinine.

used $\log$ transformed $(\mathrm{UACR}+0.5)$ as a dependent variable. Age (coefficient 0.113, $P<0.0001$ ), male gender $(-0.154, P<0.0001)$, SBP $(0.139, P<0.0001)$, serum creatinine $(0.125, P<0.0001)$, salt intake $(0.105, P<0.0001)$, smoking $(0.124, P<0.0001)$, ECG voltage $(0.056, P<$ 0.0001 ), and use of inhibitors of the renin-angiotensin system $(0.038, P<0.001)$ independently correlated with UACR after adjustment for waist circumference, uric acid, fasting plasma glucose, and dyslipidemia $\left(R^{2}=0.111, F=\right.$ 83.0, $P<0.0001)$. In line with these observations, SBP, DBP, fasting plasma glucose, and salt intake were observed to increase with increasing urinary excretion of albumin in analyses that included all subjects (Figure 2). These results were further supported by a multivariate logistic regression analysis where risks of microalbuminuria were calculated (Table 4).

\section{Discussion}

This study demonstrates that the majority of the Japanese general population has detectable albuminuria but only $4.6 \%$ present with abnormal microalbuminuria. There is a close association between urinary excretion of albumin,

Table 1 Characteristics of subjects

\begin{tabular}{|c|c|c|c|}
\hline & Total $(n=7963)$ & Male $(n=5095)$ & Female $(n=2868)$ \\
\hline Age (years old) & $56.2 \pm 11.8$ & $56.0 \pm 11.9$ & $55.6 \pm 11.7$ \\
\hline Waist circumference $(\mathrm{cm})$ & $83.3 \pm 8.7$ & $84.7 \pm 8.3$ & $81.0 \pm 8.9$ \\
\hline Body mass index $\left(\mathrm{kg} / \mathrm{m}^{2}\right)$ & $22.7 \pm 3.2$ & $23.2 \pm 3.0$ & $21.9 \pm 3.3$ \\
\hline $\mathrm{SBP}(\mathrm{mmHg})$ & $124.1 \pm 15.1$ & $125.6 \pm 14.8$ & $121.6 \pm 15.5$ \\
\hline $\mathrm{DBP}(\mathrm{mmHg})$ & $76.3 \pm 9.5$ & $77.7 \pm 9.4$ & $73.8 \pm 9.0$ \\
\hline Serum creatinine (mg/dL) & $0.76 \pm 0.22$ & $0.84 \pm 0.24$ & $0.62 \pm 0.10$ \\
\hline Uric acid (mg/dL) & $5.5 \pm 1.4$ & $6.0 \pm 1.3$ & $4.5 \pm 1.0$ \\
\hline Fasting plasma glucose (mg/dL) & $95.8 \pm 17.9$ & $98.1 \pm 19.5$ & $91.7 \pm 13.6$ \\
\hline LDL-cholesterol (mg/dL) & $118.5 \pm 26.9$ & $118.5 \pm 27.0$ & $118.4 \pm 26.7$ \\
\hline HDL-cholesterol (mg/dL) & $58.5 \pm 13.8$ & $55.6 \pm 13.1$ & $63.8 \pm 13.5$ \\
\hline Triglyceride (mg/dL) & $107.8 \pm 71.4$ & $119.9 \pm 80.7$ & $86.2 \pm 43.4$ \\
\hline Urinary albumin (mg/g Cr) & $3.89 \pm 2.02$ & $3.84 \pm 2.13$ & $3.94 \pm 1.81$ \\
\hline Estimated salt intake (g/day) & $10.9 \pm 3.4$ & $12.3 \pm 3.1$ & $8.3 \pm 2.1$ \\
\hline Current smoking (n [\%]) & $1692[21.2 \%]$ & $1547[30.4 \%]$ & $145[5.1 \%]$ \\
\hline ECG voltage ${ }^{a}(m V)$ & $2.21 \pm 0.93$ & $2.33 \pm 0.97$ & $2.00 \pm 0.82$ \\
\hline
\end{tabular}

Values are the mean \pm standard deviation or the number of subjects, except for urine albumin (median \pm absolute deviation). SBP indicates systolic blood pressure; DBP, diastolic blood pressure; LDL, low-density lipoprotein; HDL, high-density lipoprotein, $\mathrm{Cr}$; creatinine.

${ }^{\mathrm{a}}$ Electrocardiogram voltage $\left(\mathrm{SV}_{1}+\mathrm{RV}_{5}\right)$. 
Table 2 Results of univariate analyses demonstrating the relationship between urinary albumin and other variable

\begin{tabular}{|c|c|c|}
\hline & Standardized coefficient & $P$ value \\
\hline Age & 0.251 & $<0.0001$ \\
\hline Gender; male & 0.040 & $<0.001$ \\
\hline Waist circumference & 0.120 & $<0.0001$ \\
\hline Body mass index & 0.076 & $<0.0001$ \\
\hline SBP & 0.243 & $<0.0001$ \\
\hline Serum creatinine & 0.116 & $<0.0001$ \\
\hline Uric acid & 0.043 & $<0.001$ \\
\hline Fasting plasma glucose & 0.221 & $<0.0001$ \\
\hline LDL-cholesterol & -0.006 & 0.61 \\
\hline HDL-cholesterol & -0.057 & $<0.0001$ \\
\hline Triglyceride & 0.075 & $<0.0001$ \\
\hline Dyslipidemia & 0.077 & $<0.0001$ \\
\hline Estimated salt intake & 0.209 & $<0.0001$ \\
\hline Current smoking & 0.015 & 0.21 \\
\hline ECG voltage ${ }^{a}$ & 0.099 & $<0.0001$ \\
\hline RAS inhibitors & 0.145 & $<0.0001$ \\
\hline
\end{tabular}

Univariate analysis was conducted in subjects with detectable urinary albumin $(\mathrm{n}=7265)$. SBP indicates systolic blood pressure; LDL, low-density lipoprotein; $\mathrm{HDL}$, high-density lipoprotein; RAS, renin-angiotensin system.

${ }^{\mathrm{a} E l e c t r o c a r d i o g r a m}$ voltage $\left(\mathrm{SV}_{1}+\mathrm{RV}_{5}\right)$

even in normal range, and cardiovascular morbidity and mortality. This association suggests that an approach of reducing urinary albumin could be used to prevent cardiovascular disease, which is a leading cause of death. Lifestyle modification is one possible mechanism to improve

Table 3 Multivariate regression analysis demonstrates the relationship of urinary excretion of albumin to other variables

\begin{tabular}{|c|c|c|}
\hline & \multicolumn{2}{|c|}{$R^{2}=0.163, F=117.4, P<0.0001$} \\
\hline & Standardized coefficient & $P$ value \\
\hline Age & 0.152 & $<0.0001$ \\
\hline Gender; male & -0.215 & $<0.0001$ \\
\hline Waist circumference & -0.017 & 0.16 \\
\hline SBP & 0.130 & $<0.0001$ \\
\hline Serum creatinine & 0.135 & $<0.0001$ \\
\hline Uric acid & -0.004 & 0.76 \\
\hline Fasting plasma glucose & 0.155 & $<0.0001$ \\
\hline Dyslipidemia & 0.006 & 0.59 \\
\hline Estimated salt intake & 0.185 & $<0.0001$ \\
\hline Current smoking & 0.103 & $<0.0001$ \\
\hline ECG voltage $e^{a}$ & 0.055 & $<0.0001$ \\
\hline RAS inhibitors & 0.054 & $<0.0001$ \\
\hline
\end{tabular}

Analysis in subjects with detectable urinary albumin $(n=7265)$.

SBP indicates systolic blood pressure; RAS, renin-angiotensin system.

${ }^{a}$ Electrocardiogram voltage $\left(\mathrm{SV}_{1}+\mathrm{RV}_{5}\right)$. urinary excretion of albumin because both salt intake and SBP independently correlate with urinary albumin.

Several studies have reported on the prevalence of microalbuminuria in the general population including 7\% of subjects in the PREVEND study, and $3.8 \%$ of subjects in the INTERMAP study. The prevalence of subjects with microalbuminuria in those studies are similar to the present study [13,14]. In contrast, the Takahata study reported that the prevalence of microalbuminuria was $13.7 \%$ in the general population [15]. We observed that the excretion of urinary albumin is closely associated with age, male gender, blood pressure, salt intake, and various other factors. Thus, the discrepancy in the prevalence of microalbuminuria between the present study and previous studies may be attributable to differences in the characteristics of the subjects studied. Indeed, the mean age was older and the blood pressure was higher in the Takahata study than in the present study. A linear correlation of urinary excretion of albumin with future cardiovascular and non-cardiovascular death was observed in the PREVEND study and the adjusted hazard of major cardiovascular events was increased by $5.9 \%$ for every $0.4 \mathrm{mg} /$ mmol increase in UACR levels in the HOPE trial $[1,7]$. These studies demonstrate that even small increases in urinary excretion of albumin within the 'normal level' can increase the risk of future cardiovascular events. Furthermore, a reduction in urinary albumin levels is associated with a reduction in cardiovascular events $[16,17]$. These observations suggest that urinary excretion of albumin may be a surrogate marker that will useful for the evaluation of individual risk in clinical settings. The findings of others in combination with the findings of this study indicate that many people may benefit from intensive intervention to reduce or normalize the urinary excretion of albumin.

The beneficial effects of inhibitors of the reninangiotensin system on urinary albumin have already been established [13,18-20]. However, in most cases medical intervention is not realistic because of the wide prevalence of albuminuria, including 'normal' albuminuria, in the general population. A public health approach aimed at lifestyle modification that includes restriction of salt intake and high calorie diet, may be effective, because of the observed close relationship between urinary excretion of albumin and salt intake, SBP, and fasting plasma glucose.

Although the present study does not establish a causal relationship between the urinary excretion of albumin with other factors, several mechanisms underlying the observed relationship can be proposed. The kidney is an important target organ of hypertension and the relationship between increased blood pressure and albuminuria has been established. Excess salt intake produces an excess volume load and, thereby, causes an increase in 


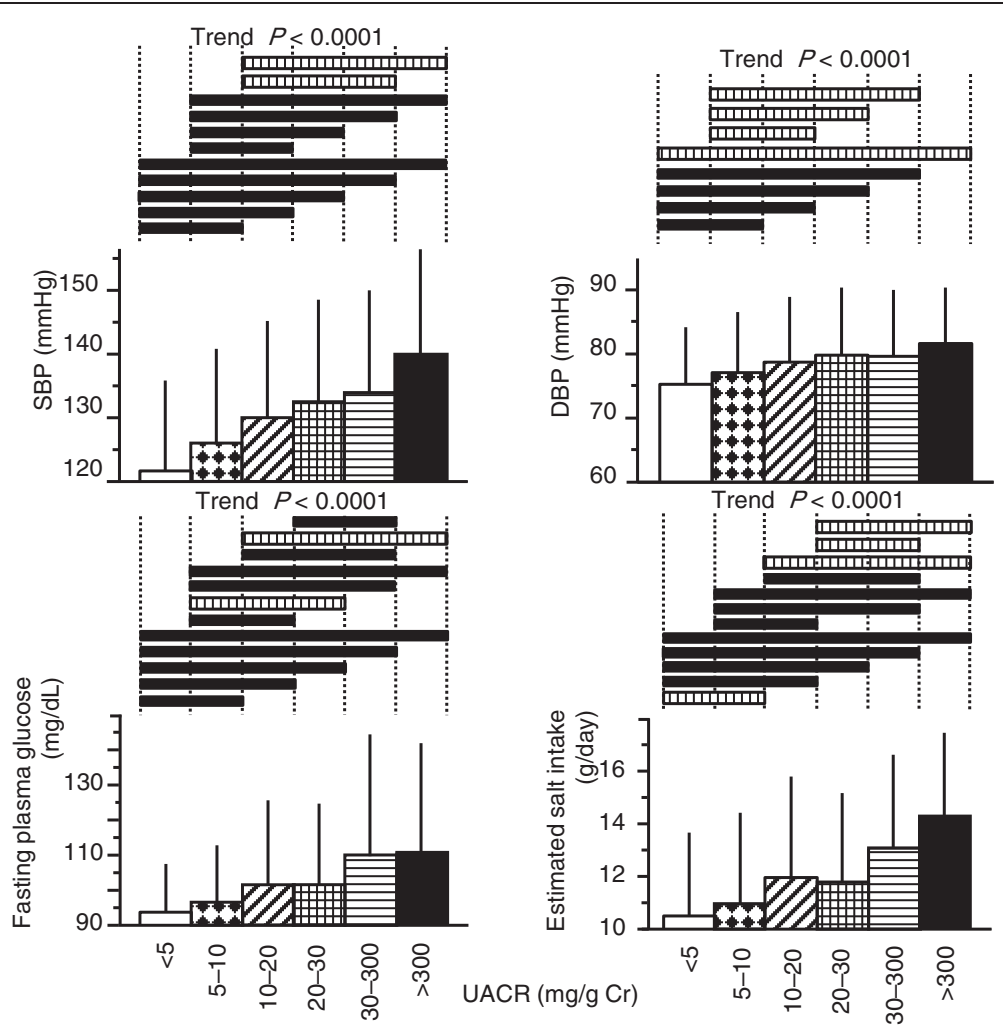

Figure 2 The relationship of urinary albumin with blood pressure, plasma glucose, and salt intake $(\mathbf{n}=\mathbf{7 9 6 3})$. The solid and hatched horizontal bars in the upper part of the figure denote that a significant difference was determined by Scheffe's post-hoc test with $P<0.001$ or $P<0.05$, respectively. UACR indicates the ratio of the concentrations of urinary albumin to urinary creatinine.

intra-glomerular pressure and glomerular hyperfiltration, which results in urinary excretion of albumin. An increase in blood pressure is also involved in the mechanism underlying salt-induced albuminuria. An elevated fasting plasma glucose level indicates the presence of

Table 4 Results of logistic regression analysis demonstrating a risk of microalbuminuria

\begin{tabular}{lll}
\hline & Odd's ratio $(95 \% \mathrm{Cl})$ & $\boldsymbol{P}$ value \\
\hline Age (years) & $1.047(1.035-1.059)$ & $<0.0001$ \\
Gender; male & $0.467(0.324-0.671)$ & $<0.0001$ \\
Waist circumference $(\mathrm{cm})$ & $1.010(0.996-1.024)$ & 0.16 \\
SBP $(\mathrm{mmHg})$ & $1.027(1.020-1.035)$ & $<0.0001$ \\
Serum creatinine $(\mathrm{mg} / \mathrm{dL})$ & $7.090(3.863-13.015)$ & $<0.0001$ \\
Uric acid (mg/dL) & $1.081(0.983-1.188)$ & 0.11 \\
Fasting plasma glucose $(\mathrm{mg} / \mathrm{dL})$ & $1.019(1.015-1.023)$ & $<0.0001$ \\
Dyslipidemia & $1.132(0.908-1.412)$ & 0.27 \\
Estimated salt intake $(\mathrm{g} / \mathrm{day})$ & $1.142(1.103-1.183)$ & $<0.0001$ \\
Current smoking & $2.040(1.553-2.681)$ & $<0.0001$ \\
ECG voltage $^{\mathrm{a}}$ & $1.151(1.030-1.285)$ & $<0.05$ \\
RAS inhibitors & $1.485(1.150-1.917)$ & $<0.01$ \\
\hline
\end{tabular}

Logistic analysis in all subjects $(\mathrm{n}=7963)$.

SBP indicates systolic blood pressure; RAS, renin-angiotensin system.

${ }^{\text {aE}}$ Electrocardiogram voltage $\left(\mathrm{SV}_{1}+\mathrm{RV}_{5}\right)$. insulin resistance that promotes sodium re-absorption and may increase the volume load. Alternatively, endothelial dysfunction may be involved in the mechanism underlying the observed relationship between urinary excretion of albumin and other factors [21-23]. Many factors that have a close association with the urinary excretion of albumin in the present study also promote atherosclerosis. Since endothelial dysfunction is an early step of atherosclerosis, these factors may cause urinary albumin excretion via endothelial damage [24]. Indeed, in the Hoorn study, a linear association of microalbuminuria with endothelium function as assessed by flow-mediated vasodilation was observed in subjects either with or without diabetes [22]. Furthermore, inhibition of the endothelial nitric oxide pathway causes albuminuria [23]. The positive correlation between the use of inhibitors of the renin-angiotensin system and urinary albumin may have been attributable to high prevalence of microalbuminuria among hypertensive patients as compared to normotensive subjects. Alternatively, patients with albuminuria may have been preferably prescribed with renin-angiotensin system inhibitors though the prevalence of microalbuminuria was not significantly different between hypertensive patients with and without renin-angiotensin system inhibitors (data not shown). 
The interpretation of the present study is limited by the following conditions. Firstly, the urinary excretion of albumin was measured only once. Secondly, study subjects were participants in our health checkup program, which could introduce a selection bias. Thirdly, clinical significance of albuminuria as a cardiovascular risk was not assessed in the present study. Finally, a causal relationship cannot be established because this was a cross-sectional study. Longitudinal follow-up studies are necessary to draw a definite conclusion.

\section{Conclusion}

The majority of the general population has detectable urinary excretion of albumin and $4.6 \%$ show microalbuminuria. The urinary excretion of albumin was shown to be closely associated with salt intake as well as blood pressure. These data indicate the importance of dietary salt restriction for the prevention of cardiovascular disease as well as end-stage renal disease.

\section{Abbreviations}

UACR: The ratio of urinary albumin to creatinine concentrations; Cr: Creatinine; ECG: Electrocardiogram; SBP: Systolic blood pressure; DBP: Diastolic blood pressure; LDL-cholesterol: Low-density lipoproteincholesterol; HDL-cholesterol: High-density lipoprotein-cholesterol.

\section{Competing interests}

The authors declare that they have no competing interests.

\section{Authors' contributions}

ST analyzed data and mainly drafted the manuscript. HT participated in the design of the study, substantially contributed to the acquisition of data. YD substantially designed the study, substantially contributed to the interpretation of the data, and critically revised the manuscript. GK participated in the design of the study and contributed to the interpretation of the data. All the authors have read and approved the final manuscript.

\section{Author details}

'Department of Cardio-Renal Medicine and Hypertension, Nagoya City University Graduate School of Medical Sciences, Nagoya, Japan. ${ }^{2}$ Department of Internal Medicine, Enshu Hospital, Hamamatsu, Japan. ${ }^{3}$ Department of Internal Medicine, Asahi Rousai Hospital, Owariasahi, Japan.

Received: 7 February 2013 Accepted: 3 July 2013

Published: 7 July 2013

\section{References}

1. Gerstein HC, Mann JF, Yi Q, Zinman B, Dinneen SF, Hoogwerf B, Halle JP, Young J, Rashkow A, Joyce C, Nawaz S, Yusuf S: Albuminuria and risk of cardiovascular events, death, and heart failure in diabetic and nondiabetic individuals. JAMA 2001, 286:421-426.

2. Adler Al, Stevens RJ, Manley SE, Bilous RW, Cull CA, Holman RR: Development and progression of nephropathy in type 2 diabetes: the United Kingdom Prospective Diabetes Study (UKPDS 64). Kidney Int 2003, 63:225-232

3. Wachtell $\mathrm{K}$, Ibsen $\mathrm{H}$, Olsen MH, Borch-Johnsen $\mathrm{K}$, Lindholm LH, Mogensen CE, Dahlof B, Devereux RB, Beevers G, de Faire U, Fyhrquist F, Julius S, Kjeldsen SE, Kristianson K, Lederballe-Pedersen O, Nieminen MS, Okin PM, Omvik P, Oparil S, Wedel H, Snapinn SM, Aurup P: Albuminuria and cardiovascular risk in hypertensive patients with left ventricular hypertrophy: the LIFE study. Ann Intern Med 2003, 139:901-906.

4. Yokoyama $\mathrm{H}$, Aoki $\mathrm{T}$, Imahori M, Kuramitsu M: Subclinical atherosclerosis is increased in type 2 diabetic patients with microalbuminuria evaluated by intima-media thickness and pulse wave velocity. Kidney Int 2004 $66: 448-454$.
5. Chico A, Tomas A, Novials A: Silent myocardial ischemia is associated with autonomic neuropathy and other cardiovascular risk factors in type 1 and type 2 diabetic subjects, especially in those with microalbuminuria. Endocrine 2005, 27:213-217.

6. Weir MR: Microalbuminuria and cardiovascular disease. Clin J Am Soc Nephrol 2007, 2:581-590.

7. Hillege HL, Fidler V, Diercks GF, van Gilst WH, de Zeeuw D, van Veldhuisen DJ, Gans RO, Janssen WM, Grobbee DE, de Jong PE: Urinary albumin excretion predicts cardiovascular and noncardiovascular mortality in general population. Circulation 2002, 106:1777-1782.

8. Matsushita K, van der Velde M, Astor BC, Woodward M, Levey AS, de Jong PE, Coresh J, Gansevoort RT: Association of estimated glomerular filtration rate and albuminuria with all-cause and cardiovascular mortality in general population cohorts: a collaborative meta-analysis. Lancet 2010, 375:2073-2081.

9. American Diabetes Association: Clinical Practice Recommendations 2001. Diabetes care 2001, 24(Suppl 1):S69-72.

10. Mattix HJ, Hsu CY, Shaykevich S, Curhan G: Use of the albumin/creatinine ratio to detect microalbuminuria: implications of sex and race. J Am Soc Nephrol 2002, 13:1034-1039.

11. Kamata K, Tochikubo O: Estimation of 24-h urinary sodium excretion using lean body mass and overnight urine collected by a pipe-sampling method. J Hypertens 2002, 20:2191-2197.

12. Teramoto T, Sasaki J, Ueshima H, Egusa G, Kinoshita M, Shimamoto K, Daida H, Biro S, Hirobe K, Funahashi T, Yokote K, Yokode M: Diagnostic criteria for dyslipidemia. Executive summary of Japan Atherosclerosis Society (JAS) guideline for diagnosis and prevention of atherosclerotic cardiovascular diseases for Japanese. J Atheroscler Thromb 2007, 14:155-158.

13. Monster TB, Janssen WM, de Jong PE, den Berg LT DJ-V: The impact of antihypertensive drug groups on urinary albumin excretion in a nondiabetic population. Br J Clini Pharmacol 2002, 53:31-36.

14. Daviglus ML, Greenland P, Stamler J, Elliott P, Appel LJ, Carnethon MR, Chan Q, Claeys G, Kesteloot H, Miura K, Nakagawa H, Pirzada A, Steffen L, Yan LL, Zhou B, Dyer AR: Relation of nutrient intake to microalbuminuria in nondiabetic middle-aged men and women: International Population Study on Macronutrients and Blood Pressure (INTERMAP). Am J Kidney Dis 2005, 45:256-266.

15. Konta T, Hao Z, Abiko H, Ishikawa M, Takahashi T, Ikeda A, Ichikawa K, Takasaki S, Kubota I: Prevalence and risk factor analysis of microalbuminuria in Japanese general population: the Takahata study. Kidney Int 2006, 70:751-756.

16. Ibsen $\mathrm{H}$, Olsen MH, Wachtell $\mathrm{K}$, Borch-Johnsen $\mathrm{K}$, Lindholm LH, Mogensen CE, Dahlof B, Devereux RB, de Faire U, Fyhrquist F, Julius S, Kjeldsen SE, Lederballe-Pedersen O, Nieminen MS, Omvik P, Oparil S, Wan Y: Reduction in albuminuria translates to reduction in cardiovascular events in hypertensive patients: losartan intervention for endpoint reduction in hypertension study. Hypertension 2005, 45:198-202.

17. Araki S, Haneda M, Koya D, Hidaka H, Sugimoto T, Isono M, Isshiki K, Chin-Kanasaki M, Uzu T, Kashiwagi A: Reduction in microalbuminuria as an integrated indicator for renal and cardiovascular risk reduction in patients with type 2 diabetes. Diabetes 2007, 56:1727-1730.

18. Gaede P, Tarnow L, Vedel P, Parving HH, Pedersen O: Remission to normoalbuminuria during multifactorial treatment preserves kidney function in patients with type 2 diabetes and microalbuminuria. Nephrol Dial Transplant 2004, 19:2784-2788.

19. Remuzzi G, Macia M, Ruggenenti P: Prevention and treatment of diabetic renal disease in type 2 diabetes: the BENEDICT study. J Am Soc Nephrol 2006, 17(4 Suppl 2):S90-97

20. Eijkelkamp WB, Zhang Z, Remuzzi G, Parving HH, Cooper ME, Keane WF, Shahinfar S, Gleim GW, Weir MR, Brenner BM, de Zeeuw D: Albuminuria is a target for renoprotective therapy independent from blood pressure in patients with type 2 diabetic nephropathy: post hoc analysis from the Reduction of Endpoints in NIDDM with the Angiotensin II Antagonist Losartan (RENAAL) trial. J Am Soc Nephrol 2007 18:1540-1546.

21. Imai $E$, Nakajima $H$, Kaimori JY: Albumin turns on a vicious spiral of oxidative stress in renal proximal tubules. Kidney Int 2004, 66:2085-2087.

22. Stehouwer CD, Henry RM, Dekker JM, Nijpels G, Heine RJ, Bouter LM: Microalbuminuria is associated with impaired brachial artery, flowmediated vasodilation in elderly individuals without and with diabetes: 
further evidence for a link between microalbuminuria and endothelial dysfunction-the Hoorn Study. Kidney Int 2004, Suppl 92:42-44.

23. Ott C, Schneider MP, Delles C, Schlaich MP, Schmieder RE: Reduction in basal nitric oxide activity causes albuminuria. Diabetes 2011, 60:572-576

24. Deckert T, Feldt-Rasmussen B, Borch-Johnsen K, Jensen T, Kofoed-

Enevoldsen A: Albuminuria reflects widespread vascular damage.

The Steno hypothesis. Diabetologia 1989, 32:219-226.

doi:10.1186/1756-0500-6-256

Cite this article as: Tanaka et al:: The prevalence and characteristics of

microalbuminuria in the general population: a cross-sectional study.

BMC Research Notes 2013 6:256.

\section{Submit your next manuscript to BioMed Central and take full advantage of:}

- Convenient online submission

- Thorough peer review

- No space constraints or color figure charges

- Immediate publication on acceptance

- Inclusion in PubMed, CAS, Scopus and Google Scholar

- Research which is freely available for redistribution 